\title{
THE DEVELOPMENT OF THE SINGLE-CYLINDER SOLO MOTOR CYCLE.
}

BY H. D. TEAGE

(Associate MEMBER).

Thxs title needs some little qualification since at first sight it may appear to impose undue limitations on the paper. It has, however, been chosen for four main reasons:-

(1) The single-cylinder has been selected as the simplest type of engine, and because almost anything that can be said about the single-cylinder applies equally to the twin- or multi-cylinder types.

(2) Tho important considerations of distribution, synchronisation and balance of twin- and multi-cylinder engines each deserve a paper to themselves, and consequently, their inclusion would render this paper altogether too lengthy.

(3) The single-cylinder engine is an extremely popular type amongst solo riders and is well worthy of investigation.

(4) The scope was intentionally limited to the solo mount, as engines for solo and passenger machines may differ in several essentials and should not be considered together. Also it is the opinion of the author that the motor cycle which was originally. designed for conveying one person will eventually revert to this main object while the passenger machine will ultimately develop on different lines.

In discussing present day solo machines it is necessary to make a brief survey of past history, but though it would be interesting to start with the earliest types there is no need to go back to a period of much more than sixteen years ago, that is, about the time when the high-tension magneto became a general fitting. This undoubtedly proved to be one of the few outstanding milestones in motor cycle design, as all who have had experience with previous types of ignition will agree-in fact the spray carburettor, the mechanical inlet valve, the magneto and the countershaft gear are the four main landmarks in the history of the single-cylinder motor cycle; for the rest, development has been extremely slow, and although the motor cycle of to-day is undoubtedly a superior article to that of 1914 its superiority lies chiefly in details that have been developed in the natural course of events rather than as a result of seientific investigation.

In proof of this, two widely differing types of single-cylinder engine will suffice for purposes of comparison with modern

TEAGE. 
machines, though many other instances might be quoted. In 1904 the 3 h.p. Triumph began to make a name in the world and the specification was almost exactly similar to that of most 1920 singles. The detail differences were that the bore was slightly. greater than the stroke and that internal cams were used.

The original engine (see Fig. 1, Plate I.) had a ball-bearing crankshaft of normal built-up construction, side-by-side mechanically-operated valves and any individual part might be mistaken for that of a modern motor cycle engine. The $3 \mathrm{~h} . \mathrm{p}$. Triumph is given as an example of a seventeen-year old engine which was the forerunner of the present day single-cylinder engine and as showing that improvements have taken place in detail only. A second example of up-to-date engine design was the de Havilland, originally designed by Mr. G. de Havilland and afterwards developed by Messrs. C. S. and E. A. Burney. One of these engines built in 1903 is still in the possession of the author. The design embodied a solid crankshaft, a large outside flywheel, plain bearings, detachable head and mechanically-operated valves both actuated by a common cam, all of which are features of the present day Blackburne engine. Unfortunately, the engine did not reach the market till nearly ten years later when the forerunners of the now popular Blackburne began to appear. Examples may be multiplied indefinitely, and the prototype of almost every existing type of single- (and, incidentally, most twin- and multi-) cylindered engines can be found at least sixteen years ago.

Such improvements as have taken place during recent years have been largely confined to efforts to discover the most suitable compression ratio by a process of elimination and to improvements in valve gear, and though these are steps in the right direction, with but few exceptions they have not yet gone far enough.

Necessity is the mother of invention, and the adoption of the sidecar as a method of carrying a passenger showed the desirability for some form of variable gear. There were as usual a few pioneers, such as Messrs. Phelon and Moore, who were at work on the subject before the advent of the sidecar, but the sidecar was the main factor in the development of change-speed mechanism as applied to motor cycles.

However much good the sidecar has done for the motor cycle, it undoubtedly showed up some weak spots which were consequently corrected. It unfortunately did a certain amount of harm to a popular type of motor cycle, for the light sporting solo mount gradually disappeared in favour of a heavy under-geared machine suitable for sidecar work and having an engine suited rather for heavy "plugging" than for liveliness and acceleration so dear to the heart of the solo rider. The ideal solo machine can never be suitable for heavy sidecar work, and the ideal sidecar machine is bound to be too heavy and clumsy for the critical solo rider.

Specialisation is necessary in the motor cycle industry as in all others, and it is comforting to find that 1921 has brought a real 
promise of improvement in this direction. Several of our leading firms are separating their solo and sidecar mounts, and in consequence they will be able to pay more attention to the perfecting of each type.

\section{Requirements.}

Very frequently motor-cyclists, after drawing up a specification of their ideal machine, send it to the Motor Cycle Press and it is sometimes published, sometimes not. In either case the motorcyclist in question is surprised at the difference between his own and other people's opinions as to the specification of the ideal machine. The reason, however, is simple. Motor cycles are required for so many and varied uses that a machine suitable for one rider may be quite unsuitable for another. For this reason it is necessary to subdivide the heading of the solo motor cycle into three main classes:-

1. The luxurious go-anywhere touring mount.

2. The purely sporting machine.

3. The machine for the multitude.

These three elasses are capable of infinite subdivision, but as regards certain features-for instance, weight-they may be classed together.

\section{Weight.}

It is obviously undesirable for any type of machine to carry about even a pound of unnecessary weight, and until a considerable improvement is made in weight-saving no present-day machine can be called really efficient. At first sight it would appear to be a difficult matter to cut weight to any considerable extent, and it must be admitted that to make an appreciable reduction in the weight of an existing model would be an arduous and costly procoeding and that the result would not be worth the cost, though many pounds could still be saved by a careful survey of all parts. On the other hand, if the whole question of weight is carefully studied and a new machine laid out as a result of this study it will be found that a very much lighter machine can be produced at approximately the same cost.

Details must receive as much attention as the main features, as it is in details that a great deal of weight can be saved. In order to make the best possible use of weight-reduction certain features (such as outside flywheels and overhead valves) which do not appeal to all manufacturers or to the whole of the buying public, must be included in the specification. Setting aside debateable points, however, a reduction in weight of reciprocating parts is possible in most motor cycle engines, and this implies reduced loading on the bearings and a corresponding reduction in balanceweights. Plain bearings are lighter (and cheaper) than ball or roller bearings and, provided that they are reasonably loaded and 
lubricated, give perfect satisfaction, as instanced by several wellknown makes of motor cycle and nearly all cars.

Many pounds can be saved by the use of a large outside flywheel having the weight concentrated as far as possible from the crank centre. Balance-weights also can be reduced if their radius of action is increased. Valves and valve gear could be lightened in many cases with a consequent reduction in valve-spring tension, and it is hoped that in the near future magnetos may be reduced in weight to a very considerable degree. A few more ounces can usually be saved by the use of a gear-driven magneto, but this is not always the case and depends on the layout of the machine.

It is not only in the engine that weight can be saved. An engine-shaft clutch can be made much lighter than a countershaft alutch since its speed is higher. Gear-boxes are often used with no reference to the power which they are designed to transmit. Frame lugs are often quite unnecessarily heavy and the strength of the frame would be increased by scientific cutting away of these lugs. In addition, sidecars have led to the use of tubes of much heavier gauges than would be necessary for solo purposes, and in some cases heavy tubes are required in order to counteract incorrect disposition of frame members. Finally, the number of clip joints on an average motor cycle is astounding when carefully examined. On a machine recently in the possession of the author, one which is acknowledged to be one of the neatest designs on the market, there were fourteen clips exclusive of badge- and wire-clips (no speedometer was fitted) when the machine was in touring trim. All these clips add weight in addition to being unsightly and diffcult to clean, and though it must be admitted that the trouble cannot be entirely eliminated until accessory fittings are standardised, yet quite a number of olips can be eliminated by proper layout.

Since certain standard components will be used both for lightand medium-powered machines, and since in certain cases the minimum workable thickness of metal can be used on mediumpowered machines, the power/weight ratio of a 500 c.c. machine is likely to compare advantageously with that of a 350 c.c. machine; on the other hand, a first class modern 350 c.c. (or even 250 c.c.) engine is capable of producing all the power and speed required by the average tourist.

\section{Price.}

Since it is undesirable that costs should be increased in order to reduce weight, and since the ideal and the practicable do not always go hand in hand, certain compromises will be necessary, and although these compromises are to a large extent a matter of opinion it is in effecting them that the successful designer shines most.

Production methods do not come within the scope of this paper and figures are, therefore, out of the question, but the author has 
endeavoured to bear in mind the manufacturing possibilities of any suggestions which have been included. In certain cases, it is true, suggested improvements would involve increased cost, but the increase could be nullified by a corresponding reduction in other parts.

From the point of view of a large section of the buying public and the development of the industry, reduction in price is extremely important, and though in the case of the luxurious touring mount there does not appear to be very much opportunity in this direction, yet in the case of the sporting mount and the machine for the multitude there are many details in which modifications might be made in order to help towards this end.

\section{Design .}

Bearing in mind the main essentials of efficiency, light weight, low production costs, reliability and accessibility there are so many possible compromises that it would be unwise to be dogmatic, but it may be as well to deal with the advantages of certain of the less usual practices in the hope that further investigation may lead to improvements and thus help towards the perfecting of the solo motor cycle.

\section{Valve Gear.}

There has probably been more discussion on the desirability or otherwise of overhead valves than on any other question of motor cycle engine design, and the question has been complicated by. reference to unsatisfactory designs which have been used in the past. A bad design of overhead valve gear is no better, and probably considerably worse, than a good side-by-side valve arrangement, but taking into consideration fuel consumption, power and a given standard of excellence in each case, the overhead valve engine will have a slight advantage in every, case. Firstly, if the valve gear is placed in the head, it is a comparatively easy matter to provide a well shaped combustion chamber. Secondly, if the ports are equally well designed the overhead valves may be smaller and lighter to provide the same efficiency. Thirdly, a carefully designed overhead-valve cylinder is a much simpler foundry proposition and there is less likelihood of a large proportion of scrap, and, fourthly, it is easier to provide equal and adequate cooling to such parts as most need cooling.

The two greatest difficulties lie (1) in designing an overheadvalve cylinder-head which provides reasonable cooling facilities and yet is a simple moulding proposition, and (2) in devising a simple and easily made operating mechanism for inclined overhead valves.

Taking these points in the order named, inverted valves to be of adequate proportions involve a considerable increase in the diameter of the cylinder-head, since to provide sufficient cooling: for the centre of the cylinder-head they must be set fairly wide 
apart. Since also the normal valve gear necessitates the setting of the valves in line with the frame it is not easy to arrange the cooling fins in such a way as to provide proper cooling without involving costly patterns and foundry work.

Longitudinal head fins will leave an uncooled pocket at the vital spot between the valves, while transverse fins, though easy enough to mould, are almost useless as regards cooling. We are left, then, with the alternative of circumferential ribs and with the difficulty of providing enough of these to give an adequate cooling surface. Probably the most satisfactory solution of the problem is to increase the head thickness towards the centre of the head to a very considerable degree and to use the largest possible number

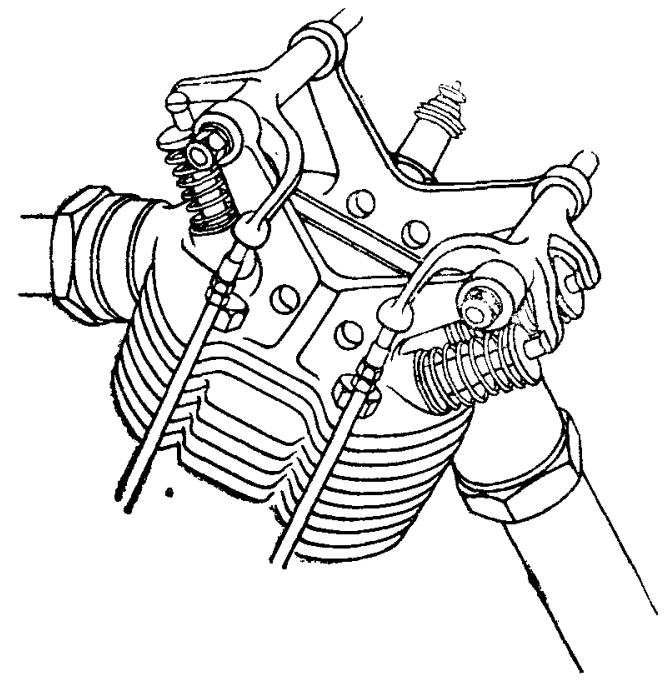

FIG. 2.

of finely pitched ribs. While on the subject of head thickness it is perhaps necessary to point out that this is one place where extra weight may be added to advantage. In order to prevent local heating and distortion a considerable body of metal is necessary. to even up the head temperature, and much "knocking" can be avoided by the use of an extra $\frac{1}{8}$ in. of cast iron in the head.

To prevent burning and distortion of exhaust valves the walls of the exhaust port should be carried up well clear of the cylinder walls, leaving a clear space for air to impinge on the casting at the junction of the port and the head.

Inclined overhead valves, especially in conjunction with a longstroke engine, provide an ideal combustion chamber and gas flow, oylinder fins of the circumferential type are easily applied and 
the foundry work is simple, as in the Nut J.A.P., Fig. 2, and the Blackburne, Fig. 3; it is not, however, easy to devise a satisfactory valve gear. An obvious solution lies in the use of an overhead camshaft carried well clear of the casting for cooling purposes. Unfortunately this involves considerable cost in bevels or skew gears, thrust races and expansion joints, though it is possible to devise a simple two-step chain drive which shall not be unduly strained by cylinder expansion. A simple method of avoiding a multiplicity of gears is used by the H.F.G. light car (see Fig. 4).

If push rods are used, both rods and rockers should be kept as light as possible, and tension rods are preferable to compression rods if this can be arranged. $\mathrm{Mr}$. Norton has devised an ingenious method of keeping down the overall height of a long-stroke over-

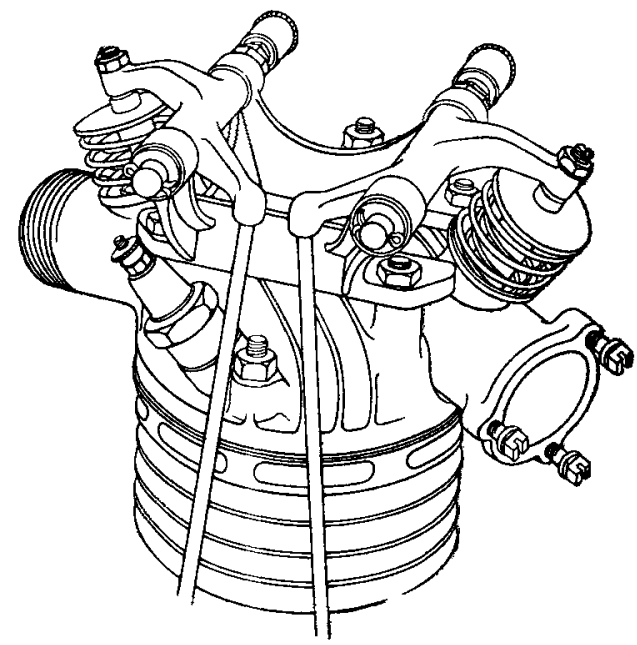

Fia. 3.

head-valve engine and operating the inclined valves. The M.A.G. engine long ago demonstrated the fact that overhead valve gear may be suitably enclosed, and a very ingenious system of enclosed valve gear is in use on the Hotchkiss light car engine, Fig. 5. This system provides a simple method of machining rocker-pivot bearings for inclined-valve engines, while the total enclosure of the valve gear keeps the push-rods warm and helps to minimise the increase in tappet clearance when the engine warms up. If push-rods are employed it is of the utmost importance that separate return springs should be fitted for the operating gear and that the valve springs should attend to the valves alone.

The stock arguments used against overhead valves are the possibility of breakage and noisiness; the first of these may be dis- 
counted by the use of carefully designed nickel, chromium or tungsten steel valves of light weight, while the second and more real trouble can be largely overcome by enclosing the valve gear, as in the case of the Hotchkiss and M.A.G. These engines are, in practice, quieter than the average side-by-side valve motor cycle ongine.

In defence of the side-by-side valve engine it must be stated that good efficiency can be obtained from this type if enough care is expended on the design of the valve ports, combustion head and cooling areas, but even after twenty years' experience the number of engines which have been so designed might be counted on the fingers of one hand.

\section{Two-Cycle Engines.}

A whole paper might easily be devoted to the subject of the two-cycle engine, and its growing popularity and increasingly

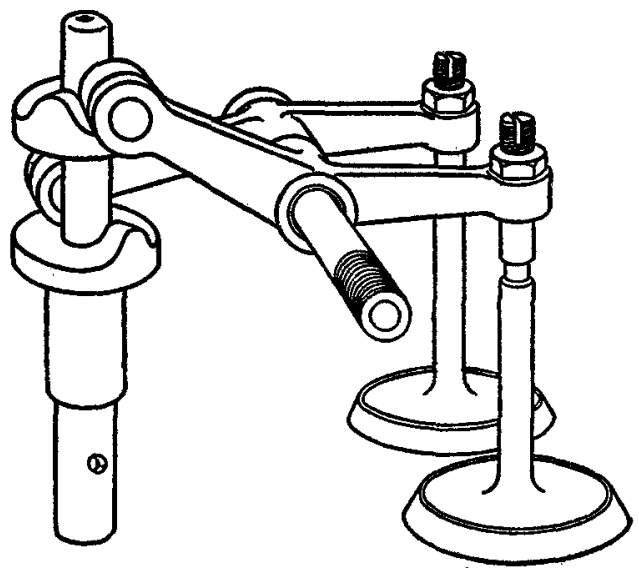

FIG. 4.

meritorious performances certainly necessitate some mention in any paper devoted to motor cycles.

On account of simplicity and ease of manufacture alone, the three-port two-cycle engine has an immense field for development, and it has already gone a long way in assisting the production of the machine for the multitude. Before it is enthusiastically received by the solo enthusiast the two-cycle engine will probably be complicated by mechanical valves, but there will be no excuse for these complications unless proportionately increased efficiency results. The author is a two-cycle enthusiast and believes that this type of engine after considerable modification will replace the majority of four-cycle engines, and that the claims on which its 


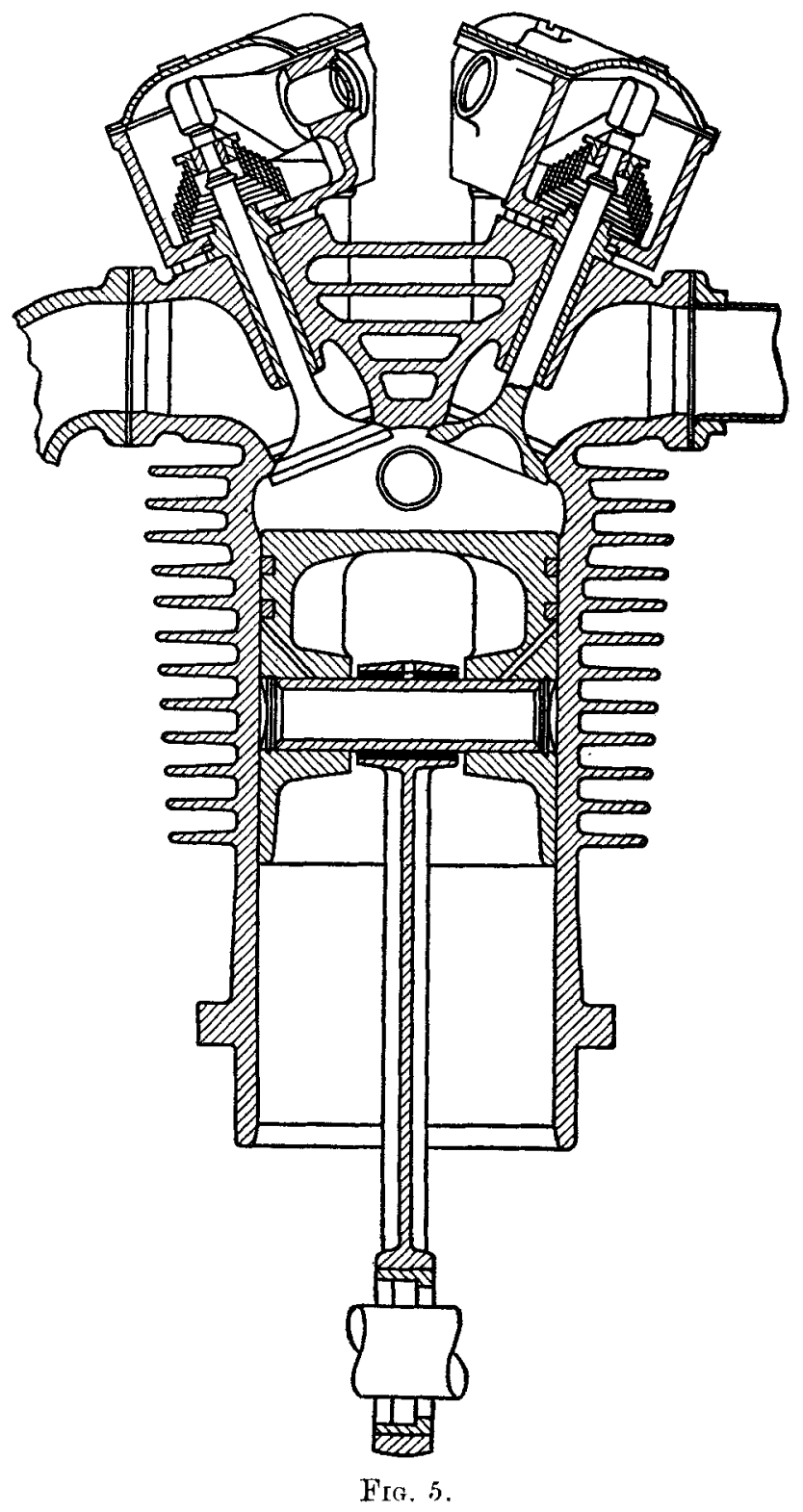


adoption will be based will be increased power per weight, and flexibility, rather than cheap production. At the present stage of progress these claims appear to be somewhat fantastic, but there are so many possible ways in which the three-port engine is obviously capable of improvement, ways which are yet untried save by amateurs, that the prospects appear to be good when an engineer backed by a reputable firm shall take the matter in hand. Such firms as the Scott, Levis, Velocette, Ivy, Connaught, Precision, and others have already developed the three-port type until it is an admitted success and competes favourably in many respects with four-cycle engines, but it is curious that in the motor cycle trade, at any rate, little has been done to develop the real high-efficiency. two-cycle engine. Further developments may, however, be expected in the near future since the problem has been taken in hand by an engine manufacturer of world-wide repute.

It is curious also that the would-be designer of a two-cycle engine is faced with an extraordinary absence of data on which to base his calculations, as such figures as are available refer almost entirely to low-speed engines such as are used in launches. Any engineer with the reputation and experience of Mr. Alfred Scott would confer a real benefit on the trade by publishing details as to the effect on brake mean effective pressure of diffierent port settings, piston deflectors, compression ratios, etc.

From certain rather crudely carried out experiments the author has come to the conclusion (though entirely open to correction) that with the normal three-port engine there is a definite relation between the crankcase and cylinder compression-ratios, and that, contrary to the generally accepted view, crank case compression can easily be too high to produce the best all round results.

Possibly one of the first additions to the three-port type will be a mechanically-operated inlet valve; the Scott Sociable (and certain Scott motor cycles) have in fact already embodied this feature, which should certainly have the effect of increasing the crank case charge and decreasing the fuel consumption. (The Ixion cycle attachment about 1903 utilised the crankshaft as a rotary inlet valve.)

A mechanical transfer valve also has many possibilities, since by delaying the closing of such a valve it would be possible to use a fixed carburettor and control on variable compression, the excess charge being returned to the crank case as in the case of the Pullin design.

The most fascinating problem, however, lies in the possibilities of direct injection. For some time past direct injection has been considered impracticable for small engines having a wide variation in loading. It may now be said that this difficulty has been largely overcome and that direct injection lies well within the bounds of possibility. This opens up the possibility of utilising: the crank case for scavenge and charging with air only, while the 
correct quantities of fuel may be introduced after all ports are closed. A single-cylinder engine on these lines with its even torque, power at low speeds and absence of valve chatter should prove ideal for solo work.

\section{Cooling.}

With the data available there should be no difficulty about cooling either a two- or four-cycle engine of any size likely to be used in motor cycle work. There are, however, many engines in which very considerable improvement can be made. Since cylinder cooling relies mainly on convection, it is essential, if the best results are to be obtained, that the ribs should be arranged so as to receive the maximum draught, and any shielding of one rib by another is undesirable. The cylinder-head is the most important part as regards cooling, the barrel, except in the case of twocycle engines, being comparatively, unimportant. Care must be taken to ensure sufficient thickness of material to even up the temperature throughout so far as is possible, and most existing motor cycle cylinders err by being on the thin side.

It is useless to employ deep radiating fins if there is insufficient thickness at the root to carry away the heat from the cylinder, and the recent practice of using long ribs "as thin as the foundry can cast them" has its origin in a mistaken theory.

It is not necessary to use aluminium or alloy cylinders to obtain good cooling if sufficient metal is used and scientifically disposed. Nor is there any need for water cooling on any single-cylinder motor cycle engine, and such a tendency would be a retrograde movement especially from the solo rider's view point. Quite possibly a considerable improvement might be obtained by careful cowling, and such cowling might reasonably form part of specially designed leg shields.

It would be presumptuous to go further into the question of cylinder cooling after the classic paper read before the Institution by Dr. Gibson during last Session.*

\section{Pistons.}

The use of aluminium pistons is the subject of much controversy at the present time. Since it is necessary to have a considerable body of metal in the head and behind the rings so as to ensure adequate cooling, the lighter metal has certain definite advantages. On the other hand, the increase in slearances rendered necessary by the greater coefficient of expansion is apt to cause piston-slap, which is objectionable to the average rider though the enthusiast may put up with it. If aluminium pistons be used and the designer prefers his own ideas to those of the manufacturers of certain proprietary pistons, it is desirable to employ plenty of

* See Proo. I.A.E., Vol. XIV., p. 243. 
metal especially in the neighbourhood of the rings rather than to cut weight to its lowest possible limit. On the whole a welldesigned cast-iron piston is preferable for touring purposes to an experimental aluminium article, though it is possible to produce excellent alloy pistons in which growth has been minimised by suitable heat-treatment. Alloy pistons were used by the winning Indian motor cycle in the 500 miles race at Brooklands and finished in perfect condition. There is little use in ribbing a piston to any great extent unless a constant circulation of oil of considerable. volume is maintained, in which case ribs appear to be helpful. For touring purposes and all normal work the piston length should be at least equal to the bore, but for racing purposes the length may be cut to 0.75 or slightly less.

Pistons for three-port two-cycle engines are bound to be on the heavy side, since the length is governed by the necessity for port sealing and the large area exposed to the explosion necessitates a considerable mass of metal to conduct the heat to the walls. Piston clearances for two-cycle engines must be kept as small as is possible, and the practice of allowing the gudgeon pin to float in the piston bosses is a good one, as normal gudgeon pin fixings are a frequent cause of distortion especially when handled by the amateur.

\section{Lubrication .}

The history of lubrication of motor eycles is of some interest since many manufacturers have used a considerable amount of ingenuity in breaking away from standard car practice; whether or no this ingenuity has been wisely expended is a matter which is open to discussion. From the earliest days the simple hand pump has found favour with motor cyclists and is still the most common form of lubrication to-day, though in many cases it is refined by sight-feed and drip attachments. Curiously enough, when trouble was experienced with plain bearings in conjunction with this somewhat crude form of lubrication, motor cycle designers decided that rather than improve the system they would evade its faults by using ball bearings wherever possible. The practice has gradually expanded until the majority of modern engines are fitted with ball or roller main and big-end bearings, while in one case rollers are used even in the small end.

This scheme has worked satisfactorily since it leaves only the piston and timing gear to the tender mercies of the novice, and once the engine has been thoroughly run in it is wonderful how much evil treatment these parts will withstand. On the other hand, though ball and roller bearings increase the efficiency of the engine to a slight degree and are desirable for the big end, espe-. cially where heavy reciprocating parts are used, they add considerably to the weight, cost and noise.

If plain bearings are to be used, mechanical lubrication is desirable, and there are two main systems which may be employed, 
each of which has much to recommend it. Either small quantities of fresh oil may be forced to vital points (as in the Phelon \& Moore), or a considerable quantity of oil may be circulated from a sump or tank. The latter system may be arranged so as to assist cooling to a very considerable extent and is the basis of a clever design by $\mathrm{Mr}$. Granville Bradshaw (see Fig. 6, Plate I.), which made its first public appearance at Olympia in 1920. To make the best use of oil circulation two pumps of considerable though unequal capacity are needed, and careful filtration is essential. It may be pointed out that the weight and cost of a simple duplex gear pump should be saved by the use of plain bearings, and a very much quieter and smoother running engine should result. Pumps to deliver small quantities of fresh oil direct to more than one bearing are apt to complicate manufacture, but the system is economical and requires less careful filtration.

It is encouraging to notice that there is a steady tendency in the direction of mechanical lubrication, and the desire for some device which relieves the rider from responsibility is evidenced by the many machines fitted with various mechanical lubricating attachments. It is, of course, desirable that oil supply should vary with load rather than with speed, and it is not a difficult matter to arrange this by interconnecting throttle and relief valves or by such means as are employed on the Sheffield Henderson, which utilises an injector effect obtained from the flow of exhaust gas.

The lubrication of two-cycle engines is a somewhat complex matter. The "petroil " system gives remarkably good results and is a very simple method of proportioning oil supply to load; it has, however; the disadvantage of being messy. The Scott system of timed crank-case suction is simple and ingenious, and the Levis employ an admirable scheme for introducing oil to the parts which most require lubrication. On the Velocette is to be found the only mechanical oiling system and this has been admirably worked out.

Excess oil in the crank case makes its presence felt in a much more objectionable manner than in the case of a four-cycle engine, and consequently a dry sump lubrication system appears desirable. This end may be achieved in two ways. The simplest is to utilise a release valve in the lowest part of the crank case to drain the sump, and the pressure thus generated may be utilised to circulate the supply; a system on these lines is embodied in the new Hawker two-cycle engine, Fig. 7.

The same end may be obtained in a more positive manner by the use of a plunger pump arranged to draw oil from the lowest part of the crank case; if necessary, this pump could be timed to operate on every explosion stroke or every alternate stroke, involving a very slight increase in cost which would probably be well repaid by the advantages gained. 


\section{Carburation and Ignition.}

Such a wide choice of carburettors is now to be obtained that the choice is best left to the individual tastes of the owner. Time does not permit of a lengthy discussion on this most interesting subject, but the author would add that after careful tests it has been his experience that with a well tuned automatic carburettor petrol consumption is usually slightly better than with a two-lever carburettor. The reason for this probably lies in the fact that any alteration of air or jet controls requires an appreciable time to take full effect, with the result that over-correction is constantly. taking place with the two-lever instrument. With regard to car-

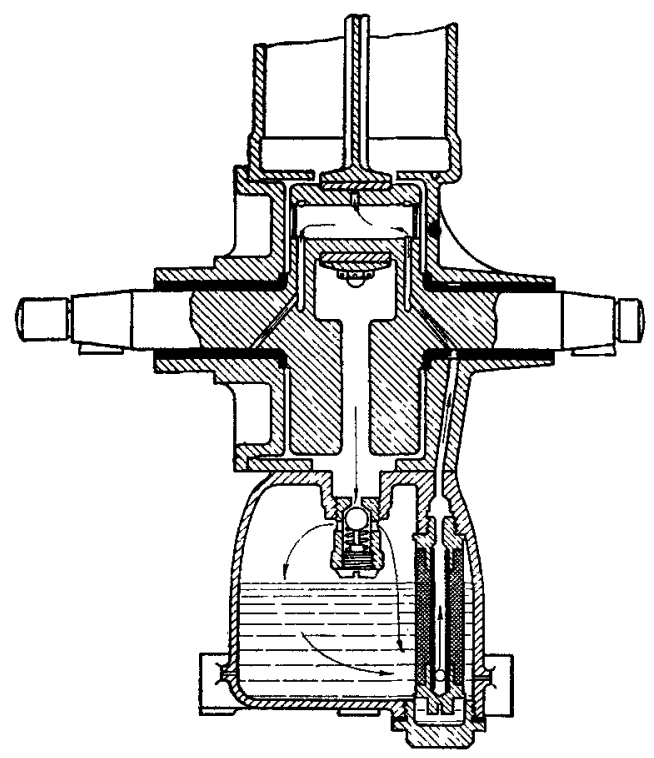

Fig. 7.

burettors for two-cycle engines it would appear that a hand-lever control for the jet is desirable, since experiments have proved that much "four-cycling" can be avoided by reducing the jet orifice when running light; there is also, of course, a reduction in fuel consumption.

Since magneto ignition is not likely to be superseded for motor cycle work there is little to be said on this subject. A plea should be made, however, for a greater range of advance and retard. Such a change would provide greatly increased flexibility, especially. on two-cycle engines; single-gear enthusiasts would also benefit to some extent. A greater range could be obtained by rocking the 
magneto as in the pre-war Mea, or by a sliding coupling with spiral grooves between the driven sprocket and the armature. Both these methods have the advantage of maintaining the break
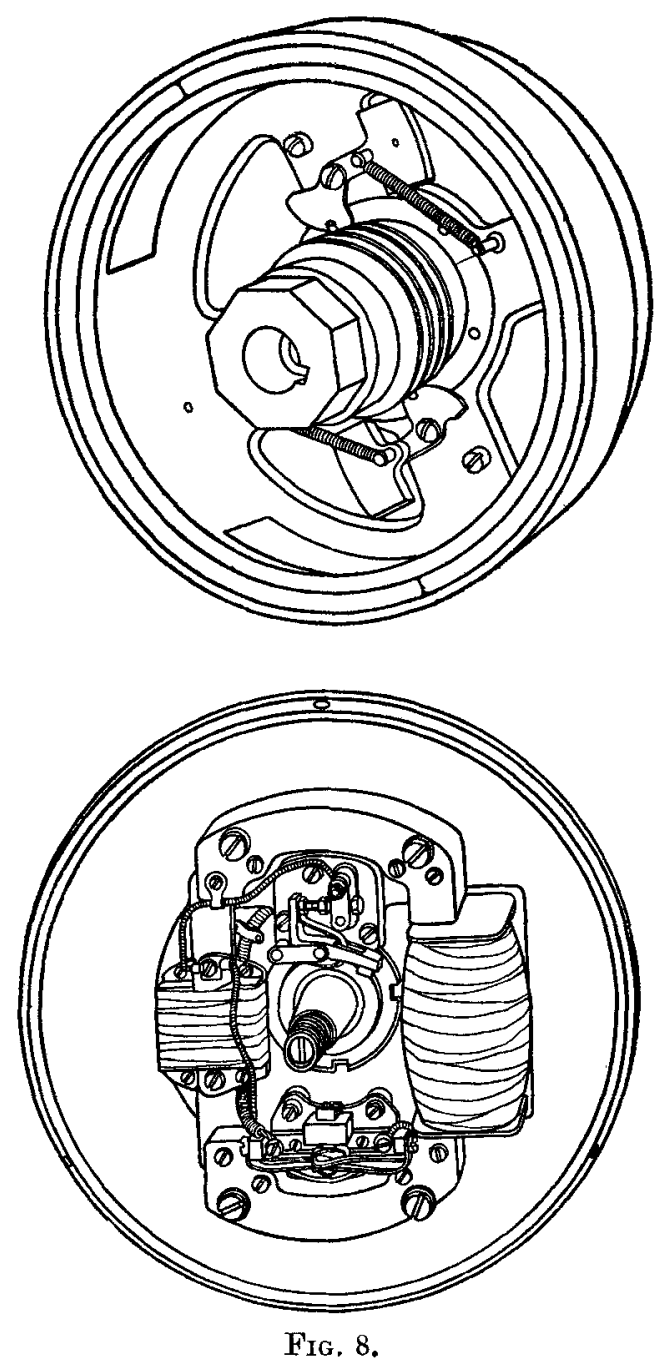

at the most efficient armature position throughout the range. Flywheel magnetos would appear to have many advantages in these respects, and it would not be surprising if they became the standard 
ignition (and possibly lighting) set for all single-cylindier twocycle engines. The B.T.H. combined arrangement is shown in Fig. 8. In addition to the advantages of increased range on maximum efficiency there should be a marked reduction in weight and cost, since the greater part of the magneto can be utilised as a. flywheel and no provision for subsidiary drives is required.

\section{Frames.}

It would appear to be impossible to fully triangulate the frame of a normal single-cylinder motor cycle. The Cotton frame, Fig. 9,

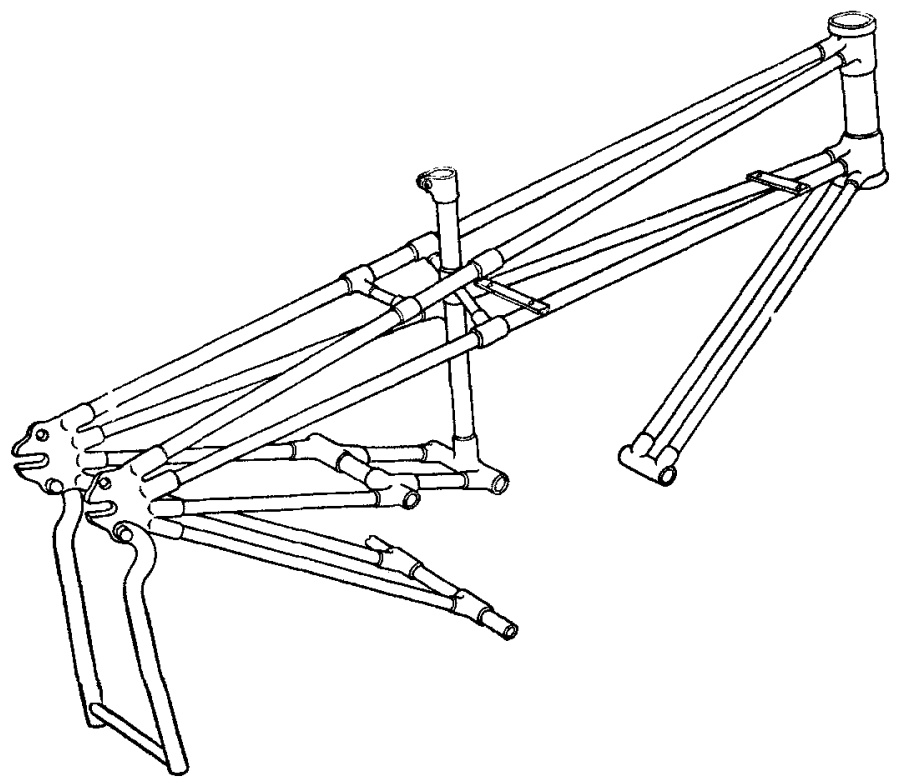

FIG. 9 .

is a serious attempt at improvement in this direction, and the sporting models of the Dutch Simplex go some way towards the desired end. Perhaps the best design, however, is that of Mr. Alfred Scott, Fig. 10, or the later T. T. Scott, Fig. 11, discussion of which is unfortunately debarred by the title of this paper. Nevertheless it would be by no means impossible to adapt such a construction to a single-cylinder engine, and it is somewhat surprising that so few attempts in this direction have yet been made.

Most existing motor cycle frames are expensive and unduly heavy, though little serious attempt has been made towards im- 
provement. Excluding forks, carrier and stand, the average motor cycle contains eight or nine tubes, no two of which are alike. Not only do they vary in length and contour, but also in section and gauge.

There is absolutely no reason why all tubes should not be

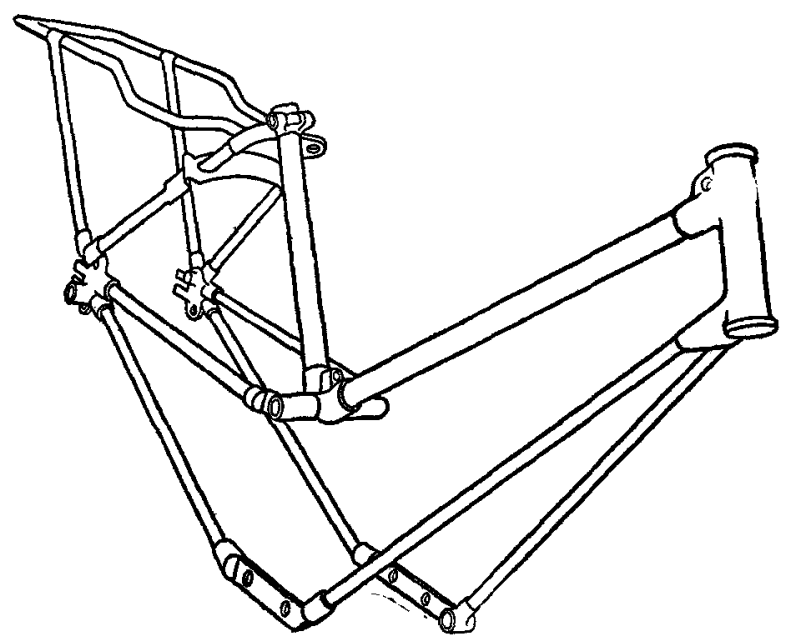

FIG. 10.

straight, and many of the heavy lugs now in common use can be either lightened or eliminated without reducing the frame strength in the slightest degree. The one place in which frame curvature is excusable under certain circumstances is in the case of a loop

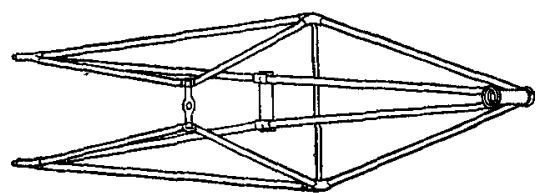

FIg. 11.

frame, which construction is preferable to joining the chain stays and down tube by badly fitted engine plates and crank case bolts. It is doubtful, however, if even a loop frame can be excused, since engine plates surrounding the crank case may be used with straight tubes.

TEAGR. 
If a detachable rear portion of the frame is deemed necessary. the attachment bolts must be a good fit in the lugs, and the rear engine plate should be rigidly attached to the saddle tube in two places, or brazed thereto as in the case of the Triumph. Brazed lugs should never terminate in square faces, since this localises the stresses, and clip joints should be avoided since they are heavy, unsightly and difficult to clean.

Steering head design calls for much criticism, and yet very little improvement has been made. There is, it is true, a tendency to fit larger ball races, but few designers appear to realise the fact that there is heavy radial loading on the head races and that the normal races used in motor cycles are unsuitable for radial loads. Cupand-cone bearings should be much more satisfactory, and it is prohable that a plain bearing head with a good sized ball thrust at the base would give results as good as or better than the more usual system of two thrust-races. The main points to watch in frame design are resistance to torsion between the head and the rear wheel spindle and the compression struts between the drive centres.

\section{Transmission.}

There are still many solo enthusiasts who prefer direct belt drive to any other form of transmission. For solo work there is much to be said for this form of drive, since it is simple, cheap and flexible. Messrs. Rudge Whitworth, Zenith and Wooler are well knowi manufacturers of satisfactory variable-pulley gears, while there are many proprietary devices which have given good results, of which probably the best known is the Philipson Governor pulley. Chain-and-belt drive is a popular compromise between the direct belt and the more positive form of all-chain drive. It is not easy to convinee the belt enthusiast that all-chain drive is not only more efficient, but, if properly carried out, smoother in action than chain-and-belt; but this is indeed the case. Chains, in order to give their best service, must be totally enclosed and must run in oil, in proof of which the author's experience with a chain-driven Triumph may be quoted. The primary drive $\left(\frac{5}{8}\right.$ in. by $\frac{1}{4} \mathrm{in}$.) was totally enclosed and ran in a bath of oil. In 9,000 miles of everyday riding, including several of the most severe motor cycle trials of the year, this was adjusted once (to take up initial stretch in the first 1,000 miles). During the same period, two rear chains ( $\frac{5}{8}$ in. by $\frac{3}{8}$ in.) have been used, and though both were in fair running order at the end of this period, both had been adjusted so ofter that the pitch must have materially lengthened. It must be remembered that the machine had been on the road every weekday and many Sundays for seven months, and that no special care had been expended on the chains.

The smooth drive of a first class chain-driven single-cylinder machine encourages the hope that shaft-drive may yet be adopted as a general rule, and it is probably due to the difficulty of 
designing a suitable frame rather than to prejudice against the shaft that this form of drive is not more usual at the present time.

It is curious that the unit engine and gear-box system has not become more popuiar in this country. The A.B.C., Clyno twocycle, Beardmore Precision and Wooler colonial models practically complete the list of existing British machines, though the Diamond, Singer, Veloce and Villiers have all built machines of this type, and the Superb Four is a promising design. On the other hand, almost every modern continental and American design embodies the gear-box with the crank case (either cast integral or bolted on). As examples may be given: French, Louis Clement, Bleriot, Louis Janoir, Gillet, Ballot (Fig. 12, Plate II.), Dutch Spring, American Ace, Henderson, Harley Davidson Sports, Indian and Scout. The unit system has many advantages, including cleanliness, lightness, cheapness. In addition, if the primary drive is by gears it eliminates an adjustment, and even if a primary chain were used the centres could be so short that it would pay to have them fixed and fit a new chain when necessary. It goes without saying that the chain or gears would be fully enclosed, and the inverted tooth type chain, though heavy, appears specially suitable for the purpose.

Once shaft-drive becomes popular, the unit system will automatically come into vogue, and in the meantime the designer of the machine for the multitude would do well to study the designs of the Clyno and the Gillet two-cycle machines. Even these designs, which employ a minimum number of gears and shafts, are capable of simplification without appreciable loss of refinement.

\section{Comfort.}

The sporting solo rider is usually prepared to put up with the minimum of luxury and comfort in exchange for a really light and "lively" machine, but comfort must be considered from the viewpoint of those who are more advanced in years and who ride solo mounts either for business or long-distance touring. Comfort is a question of degree, and though some riders are easily satisfied, others are hard to please. A spring fork is now considered an essential fitting, but there is such a divergence of opinion as to the manner of front suspension that it is clear that finality has not yet been reached.

From a consideration of the forces involved it is evident that the front wheol should be allowed to spring upwards and backwards, though there are many forks which do not permit this action. The majority of forks used in this country are of the parallel or approximately parallel link type, the forks themselves being unsprung. In America, however, the forks are usually part of the frame, the wheel being suspended on links pivoted at the fork end. This system considerably reduces unsprung weight and is very satisfactory provided that adequate bearing surfaces are provided for the pivots. A paper on "The Springing of Motor

$4(2)$ 
Cycles" was read by Mr. J. H. Savage during last Session,* sa that the various methods of suspension need not be gone into. It should be noted, however, that a very considerable amount of weight can be saved in fork design if the machine is to be used for solo purposes only.

Spring frames have been a fruitful source of discussion and much ingenuity and paper have been expended on the subject, but as far as the solo mount is concerned their inclusion in the specification should be justified by the fact that lighter parts can be used in frame manufacture, so that the total weight of the fully sprung machine is little or no greater than that of the unsprung type, and the former is equally rigid laterally. The number of spring saddle suspensions is legion, and some few of them are extremely satisfactory; for solo work it is desirable that such devices should not materially raise the saddle position.

Perhaps one of the best compromises is the fitting of larger tyres; 28 in. by 3 in. tyres on a comparatively light solo machine provide not only a very great degree of comfort, but also almost entire immunity from tyre trouble. The author has now covered some 10,000 miles (including many freak trials) on machines so fitted, with only one tyre stop due to a badly fitted security bolt. Contrary to expectation, there has been no noticeable roll though. the tyres have been ridden on the soft side, and the increase in comfort over $26 \mathrm{in}$. by $2 \frac{1}{2}$ in. tyres is most noticeable.

Comfort may be understood to include cleanliness, and while no solo motor cyclist can expect the same protection from the elements as is afforded by a car, much can be done to improve the guarding of the average motor cycle.

Very wide mudguards are not essential provided that the necessary are of the wheel is enclosed. A guard of $4 \frac{1}{2}$ in. or 5 in. wide should be ample for all purposes if it is properly valanced and extends far enough forward. In the case of the front wheel the guard should cover nearly 200 degrees of the circle, starting from a point as near the ground as clearance will allow and extendingwell forward; the lowest point should be fitted with a wide splasher as in the B.S.A. and a few other makes. This splasher is important as it protects the engine and transmission as well as the rider. The rear guard should be wide enough to cover any exposed portion of the transmission, such as belt-rim or chain-wheel, and in the case of a belt-driven machine should extend to a point well below the lowest strand of the belt, otherwise the belt will receive a copious stream of liquid mud under bad weather conditions.

\section{Recent Developments.}

The 1921 Tourist Trophy races were utilised as a means of trying out several designs which show signs of considerable ad-

* See Proc. I.A.E., Vol. XV., p. 35. 
vance. The Triumph overhead-valve engine incorporated many features of interest, including a special bronze head and masked inlet valves. With regard to the use of four overhead valves on this engine it may be surmised that the increase in number is largely due to the fact that ground clearance and frame height had to be considered, since there should be no trouble in providing. large enough single valves in an engine of this size. On the other hand, the two light valves permit very light springs and a quick opening to be employed. The B.S.A. with its vertical overhead valves and pump lubrication appeared to be a fine engine which might have made an excellent performance a fortnight later, since its preliminary troubles had been located in practice but there was not sufficient time to effect a cure before the race. Two sizes of inclined overhead-valve Blackburnes appeared and each showed itself capable of maintaining high speeds for considerable periods. The performance of the A.J.S. machines has become a matter of history and forms an illustration of what can be achieved with a small engine. Much has been said about the suitability or otherwise of this engine for touring purposes, but in the opinion of the author only slight modifications would be required to convert it intr an ideal touring machine, and the same remarks apply to the Triumph. There appears to be a general idea that highefficiency engines are necessarily unreliable, but this should not be the case since light reciprocating parts impose less strains on the bearinge, etc. No engine can maintain high efficiency for any considerable period unless it is reasonably cooled and lubricatedtwo factors which have a considerable bearing on reliability.

In addition to these engines, at least three important motor cycle factories have well designed overhead-valve engines on the road, while Mr. Bradshaw's 1,000 c.c. 90 degree twin-cylinder engine with its overhead valves and ingenious scheme of oil cooling has many possibilities. The 500-mile race at Brooklands emphasised the possibilities of the simple two-cycle engine as a fast touring machine, and a novelty in this type was introduced in the Isle of Man by the Sun Cycle Fittings Co. in their so-called radial valve engine.

The recent performances of the 250 c.c. side-by-side valve J.A.P. engines must not be overlooked, since they provide an admirable example of what is possible with well designed valve gear of this type. 


\section{THE DISCUSSION.}

The President: I hope that Members will confine themselves strictly to the solo cycle and not enter into a discussion upon the sidecar. We may then get at something which will be of value in overcoming some of the difficulties which $\mathrm{I}$ believe exist in the motor cycle to-day. I cannot claim to know much of the motor cycle, though my finst venture into the use of motors for cycling was in the year 1888 with a $2 \frac{1}{4}$ h.p. De Dion tricycle, which I converted to steam, but it was not a success. After my next venture, which was a very short one, in about 1902 or 1903 with a Kerry machine, I directed my attention to the development of industrial machines, such as steam wagons and 3-ton lorries. Some of the author's remarks, especially those referring to the frame, make me afraid of ever going on a motor cycle again. At the same time, I have ridden many hundreds of miles as a passenger in a sidecar, and have always thought that sidecar riding was very comfortable, but it has often been a matter of wonder to me that under the stresses imposed on the frame and other parts of motor cycles, especially sidecar combinations, they hold together at all.

Mr. R. H. Pearsall, in opening the discussion, said: My difficulty is that there is so little chance to-day of producing a solo motor cycle. Any firm which builds a solo machine either gives it such low power that nobody wants it, or else makes it such a good job that everyone fits a sidecar to it. Consequently, it needs all the support of the author and his colleagues to maintain in the market the conception of a pure solo motor cycle.

I do not think I can agree with the author that valves are smaller and lighter in the overhead type. The great difficulty is that the valve gear, except that of the Hispano Suisa type, is heavier, and not lighter. On page 37 there is an apparent discrepancy, because the author there states that the overhead valve makes the eylinder a much simpler foundry proposition, but later on he says that the great difficulty is to provide an overhead valve gear which is a simple moulding proposition. In connection with cooling, the author refers to finely pitched ribs, and I should like to know. why. It is perfectly simple arithmetic to work out the amount of surface, but I arn not aware of any definite determination of what is the capacity of the stream of air that actually reaches that surfaco. The B.S.A. Co., in the ordinary way, pitches the ribs $\frac{3}{8}$ in. apart, which seems to be about right. If that pitch is reduced more surface is obtained, but the question is, will the air get down to the roots of the thin fins? Personally, I am doubtful whether a pitch finer than $\frac{3}{8}$ in. 
or $\frac{5}{16}$ in is of any value. One of the most interesting suggestions in the paper is that in the two-cycle engine there is a definite relation between crank case and cylinder compression. I take it that that is a qualitative opinion of the author, but if he has any accurate data upon which he bases it, I should be very glad. to have it, because it is a subject I am much interested in, and I have not had an opportunity of arriving at a similar opinion myself yet. It is a curious thing that everybody seems to say that the two-cycle engine pulls best at low speeds, but as far as my experience goes, it is the four-cycle engine to which that applies. The ordinary two-cycle engine seems to have a narrower range of speed than the four-cycle. On page 43 the author refers to convection as the cooling factor. I am not sure that I understand the use of that word in the author's way, because surely convection depends on the temperature of the hot surface to provide its own air motion, whereas in cooling we have an impressed draught to move the air past the surface. The author also states: "The cylinder head is the most important part as regards cooling, the barrel, except in the case of two-cycle engines, being comparatively unimportant." I beg to differ. I think the great difficulty we very often have, with detachable-head cylinders is that in cylinders where the walls are not thicker than they need be, so to speak, there is no chance for the heat to be sucked down to the lower fins. It appears to me that if the walls of the cylinders are thick, with plenty of fins lower down, these fins will be enabled to do some work. Provided that the heat can be sucked dowu to the lower fins, these fins can dispose of it. The same thing applies in piston cooling, which is undoubtedly, in highefficiency engines, one of the things which must be considered very seriously. It depends, without any doubt, on keeping the system of radiation going on all the way down the barrel, so that the piston has got something to give its heat to. If the lawer fins are not provided piston life is reduced.

I once tried some experiments in the laboratory on cowling, and $\mathrm{I}$ showed that the velocity in the choke was increased, I think, some 20 per cent, so that it indicates that something of that order might be expected.* If a tunnel or a cowl is used with an area ratio of four, I do not suppose that the draught

* On reference to notes $I$ find that the choke used was 10 in. square at the leading end, 5 in. square at the trailing end and 18 in. long.

The ratio of wind velocity in the small area to the free wind velocity was-

$\begin{array}{cc}\begin{array}{c}\text { Free Velocity. } \\ \text { ft. per sec. }\end{array} & \text { Ratio. } \\ 10 & \\ 20 & 1 \cdot 62 \\ 30 & 1 \cdot 41 \\ 50 & 1 \cdot 34 \\ & 1 \cdot 26\end{array}$

These figures are points on a curve passing roughly through the actual readings. 
(Mr. R. H. Pearsall.)

on the cylinder will be increased four-fold, but probably only by an extra 20 per cent. The author suggests that racing-engine pistons may be made shorter than touring-engine pistons for reasons of cooling. Here again I beg to differ from him. If I had to design a racing-engine piston, I should make it longer than one for a touring-engine if $\mathrm{I}$ had the chance.

Next, I should like to ask the author's popinion as to the lateral stiffness of the frame of a purely solo machine. I am acquainted: with the drawbacks of the sidecar machine, but the point is, does the solo machine really need as stiff a frame sideways as the sidecar machine? I had the opportunity of testing frames in the way that the author describes, and the curious result was that two frames, which were actual commercial frames, varied in stiffness as 5 to 1 . Both of these frames were made by firms of the highest repute, but one was five times as stiff as the other, and it might be interesting to point out that the main "give" takes place on the front down-tube between the head and the tank-tube. That it is this tube that has, roughly speaking, all the work to do has been realised in the modern motor cycle of the ordinary type, since it is not only 25 per cent larger in diameter, but it is of 50 per cont thicker gauge. The chainstays also twisted about a good deal, while the bent top-tube possessed little nesistance. This shows fairly clearly that something more triangulated than the ordinary frame is required if this sidestiffness is necessary. It is very hard to get what we want in our frames, and the trouble is not so much in design as in metallurgy. We want high quality tube that we can make thin and light, but such a tube is very liable to be spoilt in brazing. We have as yet no process to take the place of brazing, and there seems to be no doubt that soldered joints are not sufficiently reliable. It is, I think, the metallurgist to whom we must look for the solution of the really light motor cycle frame as we should like to design it.

Mr. D. S. Heather: I think the President, in asking us to confine ourselves to the single-cylinder solo machine entirely, has set us an almost impossible task. I agree with $\mathrm{Mr}$. Pearsall that people will fit a sidecar on any machine which will do forty miles an hour whether designed for it or not. Many machines, the Lea Francis, the N.U.T., and the $3 \frac{1}{2}$ h.p. Sports Sunbeam, for instance, have been put on the market as purely solo machines, but I have several times seen even the last-mentioned equipped with a sidecar. It is obvious, therefore, that except in the case of very light-weight machines sidecar loads must be considered, and the frame must be made heavier than would otherwise be the case. Certainly, to-day no large firm can afford to send out a machine which is not suitable for passenger work. It is a matter of personal opinion, but I feel that there has been no development in the single-cylinder solo machino. Its main components to-day are exactly as they were many years ago. I am 
perfectly certain that if the author's 1903 de Havilland engine were to be shown at Olympia next month, people would acclaim it as a wonderful new design of high-efficiency engine by a designer obviously au fait with all the latest developments, and the same applies to many others. It is true, perhaps, that the modern engine gives more power than the old one, but whether it is more durable I should not like to say; it possesses most of the inherent faults of the old engines without doubt. In other types of engine, however, development has taken place in the transmission system and particularly in change-speed gears, but it is a question as to how far the modern rider requires a threespeed gear, and whether the gear-ratios desirable for purely solo machines are really provided. I rather think we can do with some simpler type of gear than the present heavy countershaft gear-box. The better pulling of the two-cycle engine at low speeds, which the author mentioned and $\mathrm{Mr}$. Pearsall queried, is due to its even torque, and a twin-cylinder two-cycle engine is even better. On the question of engine size, the author has not stated what, in his opinion, is a reasonable limit. We know the $250 \mathrm{cc}$. engine will give all the speed required, but whether it is desirable to give a 'man a nice big engine which will run for 10,000 miles and never need any attention, or a high-efficiency engine which will require attention, is a point for consideration. Personally, I incline to the former, because I still feel that the great disadvantage of the motor cycle from the average rider's point of view, is the amount of attention required.

The author on the first page of the paper says he is of opinion that the motor cycle will ultimately revert to its original object of carrying one passenger only, but I think that is hardly likely. The modern plea for light weight appears to me to be asking us to go back to the old type of machine, with small mudguards, small petrol tanks and a lot ;of clips that fall off. If the weight of the modern machine is analysed, it will be found that the main components are little heavier than they were fifteen years ago. The gear-box, of course, adds weight, but apart from that the modern machine is heavier simply because the fittings are better and the details better carried out and more suitable for the work to be done. Personally, I do not see how weight can be reduced very much in the design of the frame. The weight of the main frame, apart from the chain-stays and the back-stays, but including the lugs for the attachment of the engine and other parts, is from 12 to $13 \mathrm{lb}$. for a big single-cylinder machine suitable for the heaviest sidecar work, and I fail to see how any design can cut that weight down very much. The same thing applies over the whole machine. The only way to reduce the rengine weight very much is to use small high-speed, high-efficiency engines. The gear-box weight can only be reduced by running it at engine speed, which could be done by adopting a shaft drive. As regards the other parts, the tank must be a certain size, pre- 
(Mr. D. S. Heather.)

ferably bigger than at present, say, to hold $2 \frac{1}{2}$ gallons, and we can only save weight on the things we have been pleading for, such as mudguards, chain protection, etc. Generally speaking, it seems to me almost inevitable that the weight will increase, and I do not see much hope for a much lighter machine in the future. With regard to the large number of clips on some machines, I would suggest that in general it is more desirable to use clips on a frame than to use a large number of brazed lugs. I should prefer to see the number of brazed joints reduced to a minimum, seeing that every brazed joint means a chance of overheating the metal and weakening the frame. Similarly, I do not want to see innumerable little holes drilled in the frame to hold screws for Bowden wires and so on. I would far rather have clips, ugly and difficult to clean though they are.

The author states that the best chance for the two-cycle engine is in the direction of increase in power per weight. I hardly think it will ever equal, let alone improve on, the four-cycle engine on the score of maximum power, though if the author means power at slow speeds in relation to weight, say at 2,000 revs. per minute, that certainly is not only possible but it will be done. I do not understand why the author says that ball and roller bearings are desirable for the big end. I, would much rather see an engine of any type with plain big-end bearings. The roller bearings on a big end work under very difficult conditions. The velocity of the big end in relation to the crank pin is constantly changing during the whole of each revolution, which means that the velocity of the rollens is also varying, and unless there is absolutely close workmanship, the bearings will skid. The only other method is the one adopted by Mr. Lanchester many years ago when he designed a motor cycle engine, with a roller-bearing big end, in which he put such a heavy mass of metal on the big end that its centrifugal load counteracted all the other forees on the bearings and they followed the speed changes without any trouble. The plain-bearing engine with good lubrication is, in my opinion, the real ultimate goal, but it will necessarily involve extra expense, as although plain bearings are certainly cheaper than ball and roller bearings, a good lubrication system cannot be made for the difference in cost between the ball bearing and the plain bearing. The plain bearing is also much more quiet. On page 45 , the author says it is desirable that oil supply should vary with load rather than with speed. That is a statement often made, but I doubt it. I should nover foel inclined to rely on the Hawker lubrication system or on any system for twocycle engines which depends on pressure from the petrol vapour in the crankcase oil sump, as the oil would soon become too thin due to dilution with petrol. I should like to confirm the author's experience that the automatic carburettor for ordinary everyday use gives better economy and a better mixture than the two-lever type, especially where town work is concerned. The real trouble 
with the automatic carburettor is that a motor cycle is so badly cooled that when it comes to a stiff climb the mixture has to be regulated to stop pinking, and with an ordinary automatic carburettor which has not an easily accessible jet, that cannot be done. The author mentions that an adjustable jet with a hand lever is desirable for two-cycle engines. That merely shows, I take it, that a carburettor suitable for a four-cycle engine is not suitable for a two-cycle engine, which requires a different range of mixture strength. I am afraid I cannot fathom the author's reason for desiring a greater range of advance and retard of the magneto except on a two-cyole engine, where the magneto runs at engine speed, so that the actual range is half that on the fourcycle. On the latter use is never made of more than three-quarters of the range at the most, unless the ignition is too far advanoed in ordinary use. With regard to sterering-head design, the author suggests a plain bearing with a thrust race at the bottom as probably more satisfactory than the present type. In the $4 \frac{1}{4} \mathrm{~h} . \mathrm{p}$. B.S.A. machine, the stering head has thrust bearings of the usual type, with a short plain bearing at the bottom of the head to remove the strains imposed on the thrust raoe for heavy sidecar work, where the side load is considerable, and where the ordinary type of thrust race is not altogether satisfactory. In practice that is perfectly satisfactory on a sidecar machine; in fact, it is a great advantage, because the little bit of stickiness which exists in a plain bearing takes all the wobble out of the handle-bar which is present in an ordinary machine designed for solo work. For solo work, however, frequent lubrication is essential. The author's experience with chains fills me with envy, because I only get one-tenth of the mileage he quotes. If that could be obtained generally, I would give up all thought of shaft-drive, for chaindrive would be ideal.

Mr. E. CaUdWell: The author has said that plain bearings are lighter and cheaper than ball and roller bearings. I was. recently faced with this very question, and after very carefully weighing up the whole matter, we decided that the roller and ball bearings were undoubtedly cheaper. With plain bearings, extra metal is required in the housings, so that there is a slight saving in material. With ball or roller bearings the responsibility of the fits rests with the bearing makers, and it is only necessary to turn the shafts and the housings to size, and there is no fitting required, whereas plain bearings require reamering or hand fitting, and we found that there was a large saving in the fitting time required, which was more than enough to set off the extra cost of the ball bearings. Further than that, the ball bearing, to my mind, settles the lubrication problem. In order to run plain bearings sucoessfully, an oil pump and a strainer and a more or less elaborate system are necessary. With the ball bearing it is only necessary to oil the timing gears and the piston, which can be well looked after by splash, and altogether 
(Mr. E. Caudwell.)

we found, after carefully weighing up the whole matter, and considering everything involved, that the ball and roller bearing: engine was cheaper to manufacture.

I was interested to note the author's remarks on fuel injection, but I have always understood that one of the chief troubles with this system was the very minute quantities of fuel to be dealt with. A very simple calculation will show that a 3 h.p. two-cycle engine running at 2,000 revs. per minute and taking 1 pint per brake honse-power per hour, requires less than one thousandth of a $\mathrm{cu}$, in. of fuel injected into the cylinder at every explosion stroke, so that on light loads the quantity required becomes very minute. It is interesting to note that the fresh-oil injection system which the author speaks of is economical. My experience of it with American machines is very much the reverse, and that the consumption of oil is generally appalling. With any oiling system it is essential, in order to get economy, to return the oil and use it over and over again for a certain time. Reference is also made to shaft drive. I have, during the last twelve months, covered many thousands of miles on a shaft-driven, single-cylinder machine built thirteen yeans ago, and as far as I know it has been in continuous use ever since, and all the main parts are the original ones. Considering that it has an engine-shaft clutch and a high-speed gear-box, and also the lightness of the transmission, it is certainly remarkable why this type has not been developed more, but as far as I am aware, it has been produced by one firm only. This machinc seems to be extraordinarily successful, and at speeds of over ten miles per hour the drive is perfectly smooth. It is only at slow speeds that snatch pecurs in this drive. In connection with the difficulty of keeping oil from leaking out of the engine, it is a matter of surprise to me that so few people have tried the wonderful effect of the reverse-thread for this purpose. I fitted one machine $I$ had which used to be notoriously bad in this respect with a reverse-thread bush behind the sprocket and not a drop of oil has come out since; in fact, the first proof I had of its efficiency was that it was necessary to lubricate the chains.

Mr. C. TuRTLE: In the early portion of the paper, the author lays particular stress on the need for a careful study of the weights of the component parts of a motor cycle. Taking this point alone into consideration, it appears strange to me that when he comes to discuss transmission, and the combined engine and gear-box units, he should suggest that the inverted tooth type of chain, which he admits is heavy, would be specially suitable for this purpose. The actual weight of a pinion, clutch-wheel and chain for the inverted tooth type of chain as used on a leading make of 500 c.c. machine comes out at $9 \mathrm{lb}$,, while that of the corresponding parts for the roller chain is only $4 \mathrm{lb}$. From a careful study of the application, I cannot understand what benefit the author hopes to obtain from the use of the inverted tooth chain, 
as, apart from considerations of weight, the use of this type of chain on single-cylinder machines presents doubtful advantages, especially considering the impulsive nature of the torque curve of such an engine. Given cortain conditions, such as rigidity of centres, correct tension of chain, ample lubrication by means of an oil bath, and wheels with sufficient numbers of teeth, the inverted tooth type of chain will give very satisfactory results, especially from the point of view of noise. Designers should, however, realise that by careful attention to the same points, a roller chain can be made to give highly satisfactory results for the purpose in view; moreover, the roller chain is inherently more robust in general design, and consequently something that can be put into the hands of the average user without fear. An interesting example of the use of roller chains on short fixed centres has been under my notice for some time past, and only yesterday I examined a four-speed chain-driven gear-box which has run 23,000 miles on a Norton motor cycle with sidecar; the chains were all running through oil, and the box was perfectly quiet on all gears. It is interesting to note in connection with this box that the chains in the box are only $\frac{1}{2}$ in. pitch, while those from the engine to the countershaft, and from the countershaft to the near wheel, are of $\frac{5}{8}$ in. pitch. It is, indeerd, well worth the consideration of designers as to whether the smaller pitch chain cannot be satisfactorily employed for the drive from the engine to the countershaft on motor cycles, not with the idea of reducing the diameters of the present wheels, but rather with the idea of obtaining a larger number of teeth in the pinion and consequently decreasing the polygonal effect that is so detrimental to chains when running on pinions having less than nineteen teeth.

Major R. V. C. BRook: I have been using a machine for some months with an outside flywheel, and whilst it has many advantages, such as saving weight, it has one distinct disadvantage, and that is the ringing noise, which does not occur with a machine with inside flywheels, and which might be eliminated by the introduction of some damping device. Mr. Caudwell claimed that plain bearings, when all the factors are taken into consideration, are more expensive than roller or ball bearings, but since the ball or roller bearing requires practically no lubrication beyond that to prevent oxidisation, or rust, I think that with the present forms of lubrication the ball bearing has a distinct advantage. Furthermore, there is little possibility of seizure with the ball or roller bearing. On the question of design, we all realise, I think, that fashion has a very great deal to do with the selling possibilities of a machine. There have been several attempts in the past to produce machines of unorthodox design which were very promising from the practical standpoint, but which have been almost entire failures from the seling point of view, though there may have been other features, such as the smallness of the 
(Major R. V. C. Brook.)

firm producing them. In connection with valve gear, I was strongly in favour of detachable heads prior to my using my present 8 h.p. machine, because I thought it would enable me to get at the inside of the engine and clear away the carbon deposit and examine the valves much more readily than is possible with a fixed type of head, but I find that it is almost as much trouble to remove the detachable heaids as to remove the whole cylinder, and further, when the detachable heads are off, I cannot see whether the connecting rod ends are wearing, so I take the cylinder off as well, and I am "as you were" so far as the detachable head is concerned.

It has been mentioned that there is no need for aluminium to obtain sufficient cooling, but I feel that this field might be further explored. I am not sure whether we shall not have a motor cycle with detachable aluminium cylinder-heads which will give better cooling. As to the metal from which valves and valve gear are made, I am experimenting with Monel metal, which is used largely for Diesel engine valves. It is a cupro-nickel alloy of high tensile strength which is very largely constant under very high temperatures. The question of lubrication is one which: always comes up when papers such as this are read, and I think we must all agree that hand-pump lubrication is far from satisfactory. Mechanical lubrication is being tried, but we have not yet reached finality, and I do hope that manufacturers will give more attention to that question, so that ultimately we can have a machine which will run without the constant necessity for hand pumping. I am rather surprised to hear that the single-lever carburettor, in the opinion of some speakers, is more satisfactory than the two-lever instrument. Whilst the single-lever carburottor has certain advantages in the hands of the novice, I believe several leading firms have come to the conclusion that the ultimate petrol consumption is very much higher than with the two-lever carburettor. In addition, the pinking is a distinct disadvantage, and they have reverted to the two-lever type. There is one make of carburettor, the Senspray, which can be used as a single- or two-lever instrument simply by altering a little jet-damping device which is incorporated in the design.

The question of transmission is undroubtedly one of very great importance. Shaft drive, I feel, will ultimately come in, but in the meantime we must put up with the chain drive, and I am perfectly convinced that the only satisfactory chain drive is one which is totally enclosed and running in oil, not only for the front chains, but for the secondary chains as well. We all know how very much more sweetly a machine runs when the chain has been taken off and boiled in oil, or even thoroughly lubricated whilst on the machine; not only is the machine sweeter in action, but the oil has apparently a certain amount of cushioning effect in each of the rollers, whilst it also increases the life of the chain. Here I would like to mention that I have been trying the Brampton 
spring-link chain, and it has given me very good results so far as shock absorption is concerned. The only difficulty I can see about the chain so far is that it has more working parts than the ordinary roller chain, and consequently the need for lubrication is even further increased. Some manufacturers are at present fitting engines with open chains and allowing the oil released from the breather to escape on to the top of the chain. I do not think that this is of much use as the oil twill probably be flung off by centrifugal action. If the oil pipe could be arranged to throw the oil on the underside of the chain instead of on top, it would be more effective. As to comfort, there is no doubt that a machine with $28 \mathrm{in}$. wheels is very much more comfortable to ride than a machine with $26 \mathrm{in}$. wheels. I would like to say also that I think leg guards will become universal as time goes on. It is astonishing what a lot not only of mud, but of dirt and dust, is thrown on to the rider unless these are fitted, but if they are, care must be taken that the cooling of the engine is not interfered with. Finally, there is one point to be borne in mind in connection with weight reduction, and that is that a very light machine on a very bad road subjects the rider to far worse shocks than a very heavy machine.

Mr. C. S. BuRney: The author divides solo motor cycles into three classes, and I take it that Class 3 , the machine for the multitude, means something comparatively cheap, such as the single-geared two-cycle-engined machine, which should be able to travel anywhere with one up; it will therefore have to have a gear-box which brings it somewhat nearer to the luxurious goanywhere touring mount. This latter is, in many cases, used for pillion riding, which is not what it was designed for, and this necessitates, generally speaking, an engine of at least 500 c.c. Class 2, the purely sporting mount, will, I believe, eventually be a machine having a single-cylinder engine of 350 c.c. with a two-speed gear, or, alternatively, a single belt drive. The singlecylinder machine has now become so efficient that 350 c.c. is ample for all solo purposes.

I think that the 500 c.e. size will in time drop out altogether as it is unnecessarily powerful and heavy for solo use, is sometimes unmercifully used for sidecar purposes, and very often in competitions there is no class for it and it has to compete against 600 c.c. machines. Therefore, in a nutshell, I would forecast that the future solo machine will be one with a single-cylinder engine of 350 c.c., with either a two- ar a three-speed gear-box, depending on whether it is designed for sporting or touring purposes, with a small proportion of plain belt-driven machines, of course for sporting purposes only.

Valve Gear.-The valve gear of to-day is far more noisy than it was ten years ago except in a very few makes of engine, and is the cause of most of the mechanical noise of a motor cycle coupled with the fact that cylinders are thinner than they used to be, 
(Mr. C. S. Burney.)

which allows the noise of the valves dropping on their seat ta be heard. If the shape of the cam, were desigmed so that the rise and fall of the rockers is very gradual for a short distance, there would be much less valve chatter. Timing wheels, cams and rockers might also be made wider, which, owing to the oil film, would give more cushioning effect and so lessen noise, and would also increase the wearing surfaces.

Cooling.-The author states that the cylinder barrel is comparatively unimportant and I quite agree, and will illustrate it by an experiment I once made on a de Havilland engine made by me. I used a separate cylinder barrel of cast iron, $\frac{1}{8}$ in. thick, with no fins on it at all. This was quite as successful in practice as one with the normal number of fins. Another type of cy,linder barrel I used had coils of copper wire clipped round it, and still another and better one had copper fins shrunk on. Engines sloping forward in the frame, I think, give better cooling than those fitted vertically, besides bringing the centre of gravity, further forward, which is an advantage especially in these days of gear-boxes.

Lubrication. - I do not agree with the author that mechanical lubrication is desirable with plain bearings. I admit that the novice is apt to forget the hand-pump sometimes, but if he does he alone is to blame and not the engine. One well known proprietary engine was tested on the road for ten years before it was placed on the market, and this engine had plain bearings throughout and only hand-pump lubrication. I suppose about a dozen altogether of these engines were made privately during this number of years, and I did not hear of one complaint of bearing trouble, though the combined mileage must have been very great.

A constant-drip feed such as the J.A.P. which was obtained by crankcase suction has in my experience been entirely satisfactory even on the coldest of winter mornings, and this arrangement could be further improved by combining it with a Best and Lloyd throttle control. What simpler and more foolproof system could there be? Undoubtedly the supply of oil should vary with the pressure on the piston top, not with the engine revolutions, and this system would, to some extent, give it, but not so well as the standard Best and Lloyd drip-feed connected to the throttle. This arrangement takes slightly more attention, but this does not worry most riders of to-day.

Mr. F. A. S. Acres: On page 37 the author says: "A bad design of overhead valve gear is no better, and probably considerably worse, than a good side-by-side valve arrangement, but taking into consideration fuel consumption, power and a given standard of excellence in each case, the overhead valve engine will have a slight advantage in every case." In a paper read before the American Society of Automotive Engineers and published in this month's "Automobile Engineer," there is a statement which exactly contradicts the author, to the effect that an 
engine with a 4 to 1 compression ratio and side-by-side valves gave actually better results than an overhead valve engine with the same compression-ratio, other things being equal, and they were able to get these results on only 11 degrees advance of the ignition as against 64 degrees with the overhead valve engine. That was solely due to turbulence.

Mr. GRant: As a budding manufacturer of motor cycles I must disagree with $\mathrm{Mr}$. Pearsall, who deplored the lack of sufficient metal in the cylinder barrel to carry the heat away to the fins. I have always understood that the top of the cylinder is hotter than the lower part, and will expand more. By judicial design, however, the heat distribution in the cylinder can be balanced, and the bottom of the cylinder will expand equally with the top. As regards cooling and cowling, in the machine I am interested in, I am making an attempt to use the leg shields so that the whole of the engine is totally enclosed, and by suitably shaping the valance where it is opposite the engine, to get a venturi tube effect and a bigger rush of air past the cylinder. Several speakers have suggested that it is useless to design a purely solo machine, because immediately a motor cycle does 40 or 50 miles per hour, a sidecar is added I am desigining a machine that no one can put a sidecar on. I am going to market exclusively a solo machine and tell the buyer that if he puts a sidecar on it will break. In connection with engine speed, I recently analysed the A.C.U. six days' trials, and worked out the top and bottom ratios for each machine, and by using a well-known formula it could be predicted, even before the trials took place, which machines should fail. The reason is that an engine should not be driven at over a certain speed or the inertia effects of the reciprocating parts will destroy the bearings. Having selected the engine speed to suit the particular reciprocating and notating weights, the gear ratios must be chosen so that that speed is not exceeded.

I agree that the Cotton frame has too many brazed lugs, but at the same time I think that too much stress has been laid on the harm done to steel tubing by brazing. Prof. Turner, at the Birmingham University, has shown that it is possible to braze and work a metal tube, then re-heat it up to the recalescence point, about $850^{\circ} \mathrm{C}$., and let it copol down slowly in air, which will eliminate any ill effects of the brazing. I can absolutely triangulate my own frame and arrange it in such a way that $I$ can calculate to one pound the load at which any member will break, and $I$ can design the whole thing to fall to pieces on a certain hill at 70 miles an hour. My frame is, however, abnormal, and although I could guarantee it to be the lightest, at the same time I have to bear in mind the conservatism of the people in this country, and that a new design cannot be thrust on the public without slowly educating thom up to it. Consequently, I shall have to make a compromise in the frame and have a sort of

TEAGE. 
(Mr. Grant.)

semi-diamond frame. At the same time, by introducing pin joints I can guarantee what one member said in this discussion could not be done. The weight of the tubes cannot be reduced, but the weight of the frame can be reduced if brazed joints are eliminated. Any frame structure, a bridge or anything else, is designed with pin joints and then riveted. In England we rivet bridges, but in America they do not. Both stand up equally well. I suppose a motor cycle is designed with some mathematical reasoning, but that is all upset by using brazed lugs. I suggest, therefore, using pin joints as much as possible.

Mr. Trage, in replying on the discussion, said: Mr. Pearsall disagreed with my statement to the effect that the overhead valve geai would be lighter than the side-by-side gear. If he limits himself to push-rods I agree with him. On the other hand, it was mentioned in my paper that push-rods should be looked after by return springs. That, I admit, is only half an answer to the question, but I think the valves themselves could be lighter and lighter springs could be used with consequently less fear of their breakage. Certainly, if an overhead cam shaft is used, it is possible to make the reciprocating parts lighter. Mr. Pearsall rather misunderstood my remarks as to the casting of overhead:valve cylinders. What I meant was that the overhead-valve engine is an easier proposition to mould, but the most difficult part of that easier proposition is to arrange the moulding efficiently. I largely agree with $\mathrm{Mr}$. Pearsall, that ribs with less than $\frac{5}{16}$ in pitch on a normal sized cylinder are undesirable, and I put forward the suggestion of a finer pitch for a flat-headed overhead-valve engine rather as a palliative, because that type of engine has a particularly difficult cylinder-head to cool, and my suggestion was that the head should be made as thick as possible so as to include the greatest possible number of ribs and the greatest possible cooling area. I should be delighted to give more accuratie information with regand to crankcase and cylinder compression in twocycle engines if $I$ had it, but my data were purely experimental and extremely crude; I think, however, I am correct in saying that with the engine I was handling-I could vary both cylinder and crankcase compression-there wias apparently a relationship between the two. Mr. Pearsiall also disagreed with my remarks on the cooling of the cylinder barrel. My statement was founded on the results given in Dr. Gibson's paper, ${ }^{*}$ and the set of experiments which were quoted there. I agree that with detachable-head cylinders it is less important for the barrel to be cooled, but there should be some cooling between the head and the barrel, and if a detachable head is used more trouble must be taken with regard to cooling the head. The barrel temperature actually has very little effect on the power. The effect in the experiments men-

* See Proc. I.A.E., vol. XIV., p. 243. 
tioned was absolutely negligible from the practical point of view. Mr. Pearsall's next point was that the racing-engine piston should ke longer. I am not altogether in agreement with him. If sufficient bearing area can be obtained, a piston for racing purposes can be shortened, and with the object of reducing weight it is desirable to shorten it rather than to cut metal out of the inside of the piston. He emphasised the point that aluminium pistons should not bo used merely for light weight. The main feature of a good piston is the conduction to the lower part of the skirt, but I do not think it is necessary to take great precautions to conduct the heat down the whole length of the bore. Mr. Pearsall's tests for lateral rigidity in the frame were very interesting, and the weak places which he mentions are just those at which I should have expected trouble. Both Mr. Pearsall and Mr. Heather mentioned the weight of frames. I am afraid I must still maintain that the frame can be made lighter, if it is properly designed. We rely on devious methods of bolting the frame to the crank case. They are not as refined as they should be, but we rely on them for the rain strength of the frame. The down-tube fixing is, to put it mildly, rather crude from the design point of view, and I think a frame which is self-contained and does not rely on the engine can be made lighter and probably stronger. In that connection, Mr. Grant suggested normalising the frame after brazing. One well-known firm invariably put their frames through a normalising process after brazing, but whether their experiments in that direction were successful I do not know.

With regard to gear-ratios for a solo machine, it is difficult to standardise any gear-ratio because of the different types of country in which the machine may be used, but for general purposes for solo work, a two-speed gear is ample, and a low gear of 8 to 1 should take a solo machine anywhere its rider ought to want to go. I am not, of course, speaking of competition work, in which the lowest possible gear is necessary. In such work it is a question of whether the rider can sit on the machine at the speed sufficient to get up a hill, and an extremely low gear is necessary in order to keep the engine ticking over to drive the machine at a little above balancing speed. Mr. Heather mentioned the high torque of the two-cycle engine, and with certain types of twocycle engines I should be prepared to say that they will hold a given ratio a great deal longer than a four-cycle engine. That is probably due, I think, to the more even torque. Mr. Heather deprecated the idea of lubrication according to load and not speed. Perhaps he is right in the case of such engines as the oil cooled Bradshaw, which requires a very large excess of oil, but in the case of a normal oil supply it is desirable, when plugging up a hill with a heavy load, and on too high a gear (which we all know is wrong, but which the public do invariably), to give an 
(Mr. Teage.)

extra dose of oil. He suggested that the Hawker oil supply would be thinned out by dilution with petrol. I can only assure him that in practice it does not do so. I have noticed that the engine in question is not unusually economical in oil and that the supply decreases quite as rapidly as is to be expected. With regard to my plea for a greater magneto range, I was thinking perhaps rather more of the single-geared sporting machine, where flexibility is a sina qua non. The flexibility and pulling capacity at the lower speeds, which were obtainable on the old-fashioned machines with coil and accumulator ignition, where the range of timing was very considerable, were really wonderful on a high gear, and that is where the modern magneto ignition fails. I was also thinking of the two-cycle engine which has only half the range of the four-cycle.

Mr. Heather is obviously doubtful of my chain figures. I can only assure him that they are correct. Perhaps Mr. Turtle can help him on the subject. I believe my case was not an exception, because I know of one case in which there was only in $\theta$ adjustment in 12,000 miles. I am not in a position to state full details, but $\mathrm{I}$ can assure $\mathrm{Mr}$. Caudwell that direct injection has been tried successfully on engines slightly larger than those for motor cycles (a single cylinder of $100 \mathrm{~mm}$. bore). Mr. Caudwell referred to the revense-thread, and I am sorry that we did not hear something about that from Mr. Bloomfield, who many years ago originated a lubricating system depending purely on an internal thread in the bearing, which $I$ think has worked satisfactorily to this day.

Mr. Turtle's figures were most interesting, particularly as regards weights, and I know he speaks with authority. I suggested the inverted tooth chain largely for fixed-centre drives. Several speakers have stated that ball bearings are more satisfactory than plain, but I suggest that ball bearings are largely used to obviate the necessity of forced lubrication, whereas it is my opinion that forced lubrication would be more satisfactory from every point of view, not merely on bearings, as it is surely undesirable to under-lubricate pistons. Mr. Caudwell put forward the suggestion that it was cheaper to fit ball bearings than plain, and that if ball bearings were fitted further responsibility .lay with the manufacturer of the bearings. I do not think the manufacturer of ball bearings will agree with him. The fitting of ball and roller bearings, if they are to be used at all, requires a considerable amount of care--considerably more in fact than with plain bearings. Mr. Burney suggested a combination of the luxury machine and the machine for the multitude. I think that is hardly likely until manufacturers produce a four-cylinder three-speed machine for $\$ 25$. What I mean by the popular machine is the machine which will ultimately take the place of 
the pedal bicycle. He also suggested wider gear wheels for the valve gear. When I suggested that the valve gear should be lightened, I meant the reciprocating parts rather than revolving parts. I have read the paper mentioned by $\mathrm{Mr}$. Acres in the "Automobile Engineer" with extreme interest; nevertheless, I do not think that it quite washes out my previous remarks on overhead valve gear. The paper, I take it, is the one referring to turbulence. Certainly the most extraordinary results can be obtained with a side-by-side valve engine which has been designed to promote turbulence, but I do not see why equally good results should not be obtained with an overhead-valve engine which has been designed with the same object. 


\section{COMMUNICATION.}

Mr. C. H. SAvage wrote: I agree with the author when he suggests that the high-efficiency engine is not necessarily unreliable, but whether he puts as much emphasis on the "necessarily" as I do, I am not certain. High efficiency may be obtained through greater simplification, which should give reliability. At present, however, it has been obtained in niany respects by an elaboration of mechanical detail, cutting down weight and a large increase in revolutions, which I do not consider to be likely to improve the wearing qualities of the engine. I do not, however, wish my criticism to be interpreted in any way as an argument against high efficiency, and the endeavour to design a high-efficiency engine, as there can be no doubt that it is in this direction that progress lies. My point is simply that, in the hands of the engineer or skilled rider, the high-efficiency engine may give very fair results for continued riding and everyday work, as it will be nursed by riders who will appreciate and understand its possibilities and needs, while in the hands of the ordinary rider, who cannot of necessity have that particular understanding and skill, it is very doubtful if the high-efficiency engine as it is at present will be reliable.

The fact is that though high efficiency has certainly been obtained, the wearing qualities and the simplification of the necessarily additional mechanical details have not been seriously considered from the point of view of the ordinary rider, who expects his machine to run month in and month out with little care on his part, and with very low upkeep casts. Many of these high-efficiency engines are too small, and give the required horse-power by reason of their high efficiency only; this, in turn, depends on the best of fitting, small limits everywhere, and an elaborate lubricating system with possibly one particular lubricating oil.

I should like to quote another point raisied by the author, namely, that: "No engine can maintain high efficiency for any considerable period unless it is reasonably cooled and lubricated -two factors which have a considerable biearing on reliability." This seems to suggest that there is a balance in favour of the high-efficiency engine, but I should consider that both the highefficiency engine and the less efficient engine are only cooled and lubricated in proportion to their needs and with no balance on either side.

When one of these high-efficiency engines commences to wear, a condition which will be hastened by the unsympathetic riding of the inexpert, the revolutions and the power of the engine will 
fall off very rapidly. As such engines are for the most part not designed to pull well at low xevolutions, the wearing parts will have to be replaced at an early date, and the engine will probably be handed over to the tender mercies of the local cycle garage.

At present, the standard moderately efficient engine of to-day is, measured in cubic centimetres, a larger engine than its " highefficiency" brother. It is designed to give the required horsepower with less efficient fitting, upkeep and overhauling, all well within the capabilities of the ordinary rider and garage. Eventually, I suppose, our riders and the local cycle garages; at any rate in part, will be educated up to the higher standard of fitting and knowledge required by the high-efficiency engine produced on its present lines.

No human being has, however, as yet approached perfection, and while, therefore, we still have to depend on the human element to a considerable extent, and as the high-efficiency engine will always require a more specialised knowledge, it is very desirable that the more complicated mechanical detail of this engine should more nearly approach perfection, and that the foolproof qualities should be especially developed.

It is well known that users of motor transport have to keep large staff's to look over, repair and overhaul their vehicles, and high-efficiency engines must add to these troubles. 
THE SINGLE-CYLINDER SOLO MOTOR CYCLE Plate I

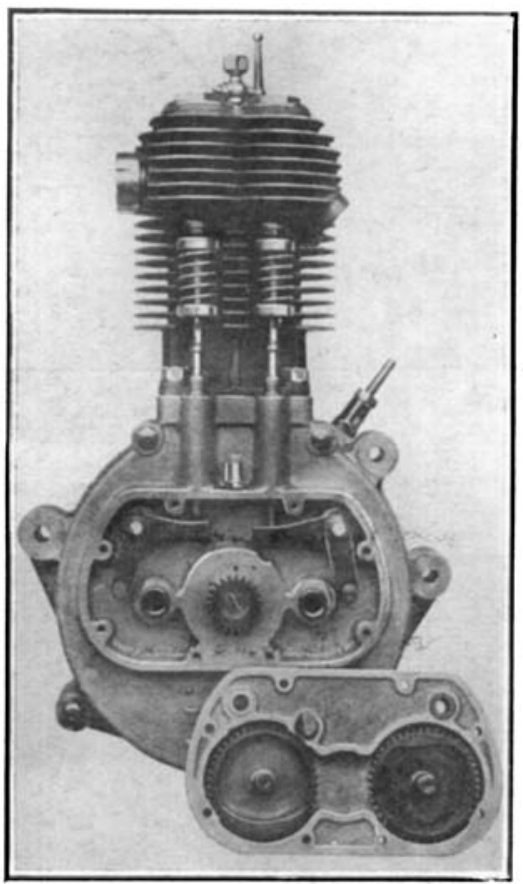

Fig. 1.-1904, 3 h.p. Triumph Engine.

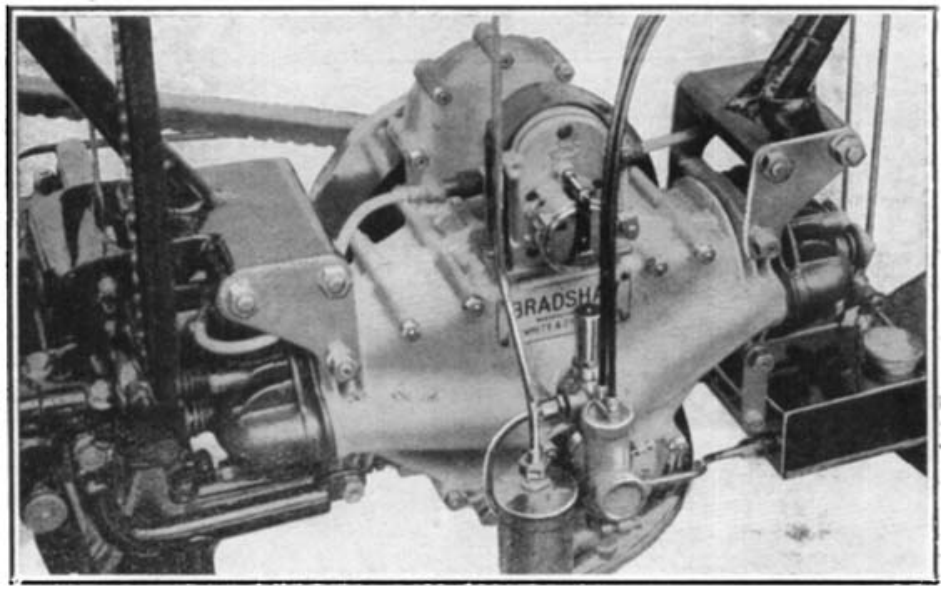

FIg. 6. 
THE SINGLE-CYLINDER SOLO MOTOR CYCLE Plate II

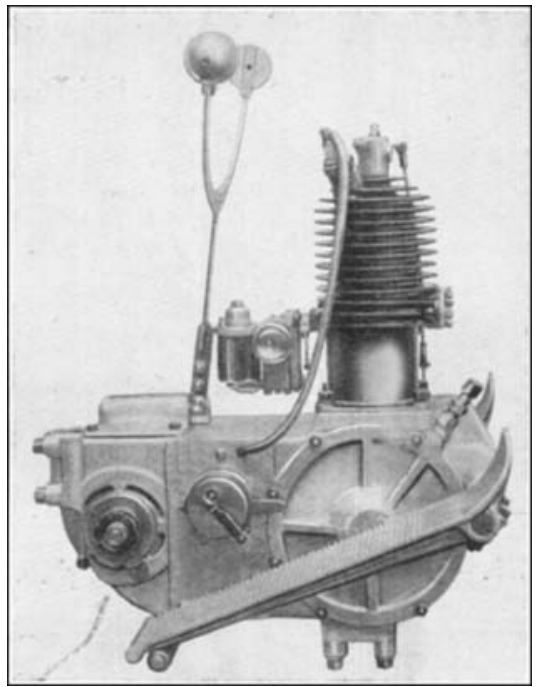

FIG. 12. 